\title{
HOST RACE FORMATION AND SYMPATRIC SPECIATION IN RHAGOLETIS FRUIT FLIES (DIPTERA: TEPHRITIDAE)
}

\author{
BY GuY L. Bush \\ Department of Zoology \\ Michigan State University \\ East Lansing, MI 48824-1115
}

\begin{abstract}
Dedication
I dedicate this contribution to my mentor, Frank M. Carpenter. His encouragement and support during my tenure as a graduate student made it possible for me to embark on a 30-year odyssey to study the process of speciation in a fascinating group of insects that do things in an extraordinary way.
\end{abstract}

In 1866 , some 200 years after the introduction of apples to North America, a local newspaper reported that larvae of an unknown fly were infesting apples (Malus pumila) in the Hudson River valley of New York (Illingworth, 1912). Shortly after the maggots were found in apples, Benjamin Walsh (1867) described the fly as Trypeta pomonella (later recognized as Rhagoletis pomonella (Snow, 1894)). Walsh's description was based on specimens reared from apples grown in eastern United States, as well as from hawthorn fruit (Crataegus spp.) gathered in Illinois where, he reported, the fly did not attack apples.

Walsh suggested that the flies infesting apples represented a newly established local host race biologically distinct from the flies associated with native hawthorn. He had proposed earlier (Walsh, 1864) that in phytophagous insects a host shift by individuals bearing a heritable change in host preference could give rise to new host races in the absence of geographic isolation. He reasoned that there would be sufficient "phytophagic isolation" (host specificity) to allow the adaptive evolution of new species. Not only was Walsh the first biologist to propose that insects could speciate sympatrically via a host shift, but he also was quite clear

Manuscript received 2 March 1993 
about what he meant by the term species. As an early and vocal advocate of Darwin in North America (Shepard, 1989), he was the first biologist to formulate what we now regard as the biological species concept (Walsh, 1863).

Although sympatric speciation remains a controversial topic, recent studies on a variety of organisms support Walsh's view that many organisms with a parasitic life style speciate sympatrically (Bush, 1993). One of the best understood examples is $R$. pomonella. A great deal of information on the ecology, behavior and genetics of this fly and its close relatives has accumulated over the years. Also, for the apple infesting population, the time of the original host shift and the pattern of dispersal throughout eastern North America are known in some detail. It is one of the few cases where the historical aspects of host race formation and its role in speciation can be studied with a considerable degree of accuracy. Here, I present an overview of the evidence, much of it resulting from research over the past thirty years, supporting the view that many Rhagoletis species have evolved in the absence of geographical isolation.

\section{Host Relationships, Host Races, and Cryptic Species}

Infestations of $R$. pomonella on apples rapidly spread throughout the apple growing regions of eastern United States and southeastern Canada, reaching western Iowa around 1890, the higher elevations of North Carolina in 1894, Nova Scotia by 1910, and southeastern Manitoba in 1916 (Bush, 1969a). Crataegus, represented by numerous species in eastern North America, is found throughout the range of the apple-associated populations. Hawthorn, extending further south into central Florida and west to central Texas, is also infested by $R$. pomonella (Berlocher and Enquist, 1993; Paine and Berlocher, in prep.), but apples grown in the southern U.S.A. are not attacked. Attempts to rear $R$. pomonella from fruits of the five native North American crabapples (Malus spp.) have failed. Our native crabapples may not be congeneric with the Eurasian representatives of Malus (Robertson et al., 1991). Their high acidity, late maturation (O'Kane, 1914), and high phenolic content (Pree, 1977) appear to render them unsuitable for larval development. Therefore, they cannot be the source of the original apple population. For this and several other 
reasons detailed elsewhere (Bush et al., 1989; Feder and Bush, $1989), R$. pomonella on apples came from native North American Crataegus.

Over the years, $R$. pomonella-like flies were found infesting the fruits of other plants such as blueberries (Vaccinium spp. and Gaylussacia spp.) (Britton, 1906), dogwood (Cornus spp.) (Hall, 1934), snowberries (Symphoricarpus spp.) (Snow, 1894), native plums (Prunus spp.) (Benjamin, 1934), tart cherries (Prunus cerasus L.) (Shervis et al., 1970; Messina and Jones, 1990), pears (Pyrus communus L.) (Prokopy and Bush, 1972), rose hips (Rosa rugosa Thumb.) (Prokopy and Berlocher, 1980), and apricots (Prunus armeniaca (L.)) (Lienk, 1970). Some of these host associated populations, such as $R$. mendax on blueberries (Curran, 1932), $R$. zephyria on snowberries (Snow, 1894), and $R$. cornivora on shrubby dogwood (Bush, 1966), are now recognized as cryptic species. Others appear to represent undescribed species, for example, populations infesting flowering dogwood (C. florida L.) (Smith, 1988a; Berlocher et al., submitted), southern populations whose larvae feed in wild plums, and populations that infest several species of blueberry in the southeastern U.S.A. (S. Berlocher, pers. comm.).

The reports of $R$. pomonella attacking the fruits of pear and apricot probably represent transient infestations since this fly has failed to establish permanent populations on these important introduced commercial fruits that are constantly scrutinized for destructive pests. However, extensive studies of $R$. pomonella, which I will discuss more fully, indicate that infestations on cultivated and feral apple represent well established populations that are distinguishable from native haw populations by several important genetically biased biological traits. The apple and haw populations represent host races that have evolved different mate recognition systems sufficient to maintain these genetic distinctions (Diehl and Bush, 1984). These differences evolved as a direct outcome of adaptation of each race to a new host in the absence of any physical barriers to gene exchange. Preliminary observations of established populations of $R$. pomonella on introduced tart cherry and rose hips suggest that they also are host races that have developed sympatrically within a very short period of time on introduced hosts. 


\section{Biological Attributes of RHAGOLETIS}

Boller and Prokopy (1976) reviewed early research on the biology of Rhagoletis. Details of the systematics and phylogenetic relationships of this genus have been summarized by Bush (1966) and Berlocher and Bush (1982). Only those aspects pertinent to host race formation and speciation are presented here.

Egg and larval development: Eggs, inserted by the female's ovipositor under the skin of the host fruit, hatch within a few days. First instar larvae work their way into the interior of the fruit and in so doing reduce their exposure to parasitism (Feder et al., in prep. b). Larval development takes as little as two weeks under optimum conditions in fruits with high sugar content and low acidity. Conversely, eggs and larvae may experience up to $100 \%$ mortality in certain varieties and species of apple and haws (Dean and Chapman, 1973; Bush et al., 1989). In temperate climate Rhagoletis species, the majority of third instar larvae leave the fruit in two to four weeks and burrow into the soil under the host tree. Pupation occurs about four inches below the soil's surface where pupae overwinter for several months in diapause (Boller and Prokopy, 1976).

Diapause and eclosion: Although most temperate climate Rhagoletis have only one generation per year, diapause is generally facultative (Prokopy, 1968). Because larvae of the apple race of $R$. pomonella are exposed to longer days than the haw race, from $1-5 \%$ of the pupae may not diapause, and a small second adult generation is produced usually too late in the season to reproduce. The apple race apparently has not completely adjusted to the shift in day length and warmer temperatures to which they are exposed. Most temperate climate Rhagoletis undergo a winter diapause which is terminated after exposure to low temperatures. Adult development in the pupa is initiated by rising temperatures in spring when soil temperature extends above a minimum threshold level. Depending on temperature and moisture conditions in the soil, about $10 \%$ of the pupae may remain in the soil for $2-5$ years before completing development. This "pupa banking" insures a reserve of adults from year to year in areas where masting of the host species may cause cyclic or sporadic drastic reductions in fruit or complete crop failure in a region. 
Each species or host race responds somewhat differently to moisture, temperature and other environmental conditions (e.g., day length) to which larvae and pupae are exposed (Prokopy, 1968; Feder et al., 1993). The physiological mechanism for controlling the rate of post-diapause development and the timing of eclosion in R. pomonella and other Rhagoletis species has not been determined, but it is highly correlated with the accumulation of thermal units over a developmental threshold temperature which varies from $4.4-8.7^{\circ} \mathrm{C}$ depending on locality, species, and method of measuring temperature (soil or air) (Reissig et al., 1979; Feder et al., 1993).

Food foraging, dispersal and longevity: Upon emergence, adults begin foraging on the surface of leaves of host and non-host plants for food such as insect honeydew, bird feces, yeast and bacteria. Both males and females in $R$. pomonella require carbohydrates, certain vitamins and amino acids for sexual maturation. Mating and oviposition begins on about the 10th to 12th day after eclosion (Webster et al., 1979). Adults begin to suffer high mortality if deprived of food for more than one day (Malavasi and Prokopy, 1992).

Rhagoletis locate vegetation primarily by vision. Before sexual maturity, adults of both sexes are strongly attracted to surfaces reflecting in the yellow portion of the spectrum $(500-600 \mathrm{~nm})$. This color, which is a major component of light reflected from green vegetation, appears to be a foliar attractant used by the flies to locate food resources (Prokopy, 1976). Both males and females orient positively to tree models of specific shape, size and color, particularly ones with shifting patterns of individual leaves (Moericke et al., 1975). Odor of food resources on the leaves may also promote the movement of flies to particular trees (Prokopy, 1976), although the odors of host or non-host foliage and twigs alone are not particularly attractive (Prokopy et al., 1973).

During this pre-copulatory period of feeding, adult Rhagoletis move continuously and can disperse some distance (Roitberg, 1982). Dispersal is influenced more by the availability of food than the search for mates and oviposition sites. Just how far the average adult is capable of moving during the feeding phase is not known, but field and laboratory flight studies indicate that they are capable of traveling several kilometers (Prokopy, 1976). 
How long Rhagoletis adults survive in nature has not been accurately established. Estimates of average longevity vary from two weeks for $R$. cerasi, three weeks for $R$. mendax, three to six weeks for $R$. completa Cresson, and up to four weeks for $R$. pomonella (Opp and Prokopy, 1987). It is clear that light, moisture, temperature, and the availability of food and oviposition sites have profound effects on adult survival rates (Boller and Prokopy, 1976).

Host plant and fruit foraging behavior: Motivation for dispersal, initially driven by the need for food, changes as flies become sexually mature. Adult $R$. pomonella continue to use the same physical cues of shape and color to locate host trees, but in addition become strongly attracted to specific odors emanating from ripening host fruit (Prokopy et al., 1973). Certain esters, identified by electroantennogram bioassays and behavioral observations, are important components eliciting response to host fruit odor (Fein et al., 1982; Averill et al., 1988; Frey et al., 1992). Once on the host plant, both sexes begin visually searching for, and are strongly attracted to, dark colored spheres approximately the size of their natural host fruit (Prokopy et al., 1971; Prokopy, 1977). Other species, such as $R$. cerasi, $R$. mendax and $R$. completa, prefer fruits of varying sizes, colors, or combinations of fruit volatiles (Guerin et al., 1982; Riedel and Hilslop, 1985; Frey et al., 1992). In the absence of fruit, flies rapidly abandon a tree and disperse in search of mates and oviposition sites on other trees (Aluja and Prokopy, 1992). Host selection is, therefore, mediated by a combination of visual, tactile, and olfactory cues, with the latter providing a crucial chemically based signal for host specificity.

Mating and oviposition behavior: Rhagoletis males and females use the host as a rendezvous for courtship and mating, a mode of mating behavior typical of many parasites (Bush, 1975; Zwölfer and Bush, 1984). Thus, the search for mates by both sexes of Rhagoletis is inexorably linked to the search for their host plant (Bush, 1969a, 1974). Therefore, the cues used to locate a mate are the same visual, tactile and chemical cues involved in the search for a host tree and fruit. At the beginning of the mating period, when most females of $R$. pomonella are unmated, matings may occur on leaves of the host plant following a courtship duet involving wing waving, posturing, and short range male pheromones (Prokopy et al., 1973; Prokopy, 1975; Smith and Prokopy, 1980). 
Once mated, females ignore males and begin to oviposit on host fruits.

Female flies inspect the surface and reject or accept a fruit for oviposition on the basis of its size, surface structure, stage of ripeness and other stimuli (Boller and Prokopy, 1976). Although most Rhagoletis species lay only one egg at a time in a maturing fruit, members of the walnut infesting $R$. suavis (Loew) species group are batch egg layers (Boyce, 1934). After egg laying, a Rhagoletis female drags her ovipositor over the surface of the fruit depositing at least two water soluble pheromones (Prokopy, 1972). In $R$. cerasi one of these pheromones has been identified as a complex molecule detected through special tarsal chemosensilla (Städler and Katsoyannos, 1979; Crnjar and Prokopy, 1982). This pheromone deters other females from laying eggs in the same fruit, and thus reduces intraspecific larval competition at least initially (Averill and Prokopy, 1989; Aluja and Boller, 1992).

At the time of ovipositor dragging, a second, short acting substance is deposited which arrests males on the fruit and informs them that a female has recently been in the vicinity (Prokopy and Bush, 1972b). This unidentified substance tends to aggregate males on the fruits in trees where females are actively ovipositing. Males of $R$. pomonella spend $89 \%$ of their time patrolling apples (Prokopy and Bush, 1973), aggressively driving away other males and attempting to forcibly copulate with arriving females (Prokopy, 1981). This enhances the chance for multiple matings, which are necessary to maintain maximum fertility (Neilson and McAllen, 1965; Opp and Prokopy, 1986). When females cease oviposition in a particular tree it is abandoned by males.

\section{Biology and Genetics of $R$. POMonella Host Races}

Host race criteria: There have been several attempts to establish criteria for distinguishing host races from populations of polyphagous generalists. Mayr (1970) regarded host races as "noninterbreeding sympatric populations that differ in biological characteristics but not, or scarcely, in morphology." They are "prevented from interbreeding by a preference for different food plants or other hosts." However, reproductive isolation is the same criterion used by Mayr to define species in his biological species concept. Others have proposed alternative host race definitions 
(Bush, 1969; Futuyma and Mayer, 1980; Jaenike, 1981; Bush and Diehl, 1982). Based on our current knowledge of recently established host specialists, host races are partially reproductively isolated, conspecific populations specializing on alternative hosts (Diehl and Bush, 1984). As discussed by Jaenike (1981) and Diehl and Bush (1984), to verify the existence of host races requires that:

1. Individuals in breeding condition of different host-associated populations must be sympatric.

2. Statistically significant genetic differences exist between these sympatric populations over several generations that are not directly related to host selection or solely the result of natural selection acting on a single generation.

3. Males and females exhibit genetic variation in host preference that results in assortative mating, i.e., mating occurs on the preferred host plant and host preference is under genetic control.

4. Males and females show host-associated tradeoffs in fitness.

5. There is no evidence of post-mating reproductive incompatibility. Hybrid incompatibility between host-associated populations indicates they are sibling species, not host races.

There is now sufficient biological and genetic evidence to show that apple and haw populations of $R$. pomonella meet all the above host race criteria.

1. Sympatry: Populations of $R$. pomonella on apple have been sympatric with the original hawthorn race from the moment this fly colonized apples in the Hudson River valley about 150 years ago. The original shift must have occurred in an area where apple trees were growing within the dispersal range of flies infesting hawthorns. Adults of Rhagoletis species are capable of colonizing stands of host plants isolated some distance from an infested tree. In a careful study of dispersal, marked $R$. cerasi flew at least 3.5 $\mathrm{km}$ in direct point-to-point flights over cleared land (Boller, 1979) and were able to reach adjacent orchards separated by $3 \mathrm{~km}$ of forests (Boller, 1987) when host fruit was unavailable for oviposition. Comparable dispersal distances were recorded in earlier studies for $R$. completa (Barnes, 1959) and $R$. pomonella (Maxwell and Parsons, 1968). Because the recovery of marked flies is low, it is likely that individual Rhagoletis adults may disperse considerably further than the recorded $3.5 \mathrm{~km}$. It is therefore unlikely that apple 
or Crataegus hosts with fruit suitable for larval development would long remain uninfested even if isolated by considerable distance from infested apples or hawthorns.

2. Genetic differences over space and time: There are several recognized genetic differences between the apple and haw races. We (Feder et al., 1988; Feder et al., 1989a; Feder et al., 1990a; Feder et al., 1990b) and our co-workers (McPheron et al., 1988) have documented allele frequency differences in six allozyme loci between paired sympatric samples of the apple and haw races throughout the northeastern United States. These frequency differences are maintained across different developmental stages of the fly as well as from year to year. Clinal allelic variation also exists at these six loci, and is highly correlated with local seasonal ambient temperatures experienced by each host race during larval development and adult activity.

While the allozyme alleles respond to clinal and seasonal temperature differences, their pattern of divergence indicates that they are genetically linked to other loci involved with adaptation to apple and haw. These adaptations include eclosion time (Smith, 1988b), response to host odors (Frey and Bush, 1990) and host fidelity (Feder et al., in prep. a). Divergent selection on these traits, discussed more fully below, contributes to the maintenance of the observed allozyme differences under sympatric conditions by reducing the effects of recombination and gene flow between the races. However, such host associated traits alone cannot be the only factors maintaining genetic differences between the host races. The allozyme results suggest that host specific assortative mating also occurs in $R$. pomonella.

3. Host preferences: Although the physical cues (color, shape, texture, etc.) used by both host races to locate a plant for feeding are the same, the electrophysiological response of $R$. pomonella to specific apple and haw odors differs significantly (Frey and Bush, 1990). This suggests they already discriminate between the two host fruits to some extent at the chemosensory level (Frey and Bush, 1990). Support for effective host fidelity based on genetically constrained host selection behavior was obtained in a recent mark-release-recapture study (Feder et al., in prep. a). Apple and haw flies showed strong preference (around 94-95\% host fidelity) for their respective host plants under natural conditions. 
Evidence for genetically based differences in host acceptance behavior has also been found (Prokopy et al., 1988). Although apple and haw fruit are equally accepted for oviposition by naive females from apple and hawthorn origin, apples are accepted significantly more often by females from apple than females from hawthorn. Males of the apple and haw races exhibit similar differences in their pattern of host acceptance. Residence times spent on haws by naive males from apple and haw are the same, while males of apple origin tend to reside substantially longer on apples than males of hawthorn origin.

Another important feature of host fruit choice in $R$. pomonella, and possibly all Rhagoletis species, is the contribution that learning (i.e., a change in behavior with experience) plays in host acceptance behavior. Both Rhagoletis apple and haw flies have the ability to learn to accept or reject novel fruit species and to accept familiar fruit species (Prokopy et al., 1982; Papaj and Prokopy, 1986; Papaj and Prokopy, 1988; Prokopy et al., 1989). Adult $R$. pomonella from apple can learn to reject unfamiliar physical and chemical stimuli of different host fruit species more readily than those from haws. They spend a significantly longer time on the same species of fruit with which they have had prior experience, and females prefer to oviposit on fruits in which they have already oviposited. Prior host fruit experience by both males and females of the apple race not only has a strong influence on what species of host fruit is preferred by males for courting females and by females for subsequent oviposition, but females (and presumably males) can also learn to discriminate between apple cultivars (Prokopy and Papaj, 1988). This discrimination, based on differences in chemical stimuli among haws and apple cultivars, should increase oviposition preference and habitat fidelity and promote genetic subdivision of the races (Papaj and Prokopy, 1988).

A further indication of host specialization is indicated by racial differences in seasonal distribution patterns. Adult eclosion in $R$. pomonella is synchronized with the ripening pattern of host fruit and differs between the host races. Under field conditions the apple race emerges about ten days to two weeks before the hawthorn race (Reissig and Smith, 1978; Feder et al., 1993). This seasonal asynchrony is the result of heritable genetic differences in development (Smith, 1988b; Feder et al, 1993). Furthermore, field studies suggest that adults of the haw race may reach sexual 
maturity somewhat slower than the apple race, further reducing the opportunity for hybridization between the races (Stanek et al., 1987; Feder et al., 1993). Although seasonal asynchrony contributes to allochronic isolation of the host races, it alone is unlikely to be sufficient to sustain racial differences in the absence of host fidelity.

4. Host associated fitness tradeoffs: Careful experiments involving reciprocal egg transplants found no evidence for host raceassociated differences in larval survivorship on either apple or haw (Prokopy et al., 1988). Furthermore, haw appears to be a more suitable larval host than apple. Larvae of both races had equally higher rates of survival on haws than on apple. This suggests that the races have not evolved larval feeding specializations for either host. But factors other than host fruit chemistry do cause hostassociated fitness tradeoffs. These tradeoffs deal with differences in the environmental conditions experienced by larvae and pupae.

A major factor affecting fitness that imposes important selective constraints on larvae and pupae of each race is host fruit phenology. Apple flies that develop too soon fail to diapause, emerging the same season, but too late to produce a second generation. Hawthorn flies that develop too slowly also fail to diapause before the onset of winter. Adaptation of each race to their respective hosts has thus required adjustments in those genes responsible for coping with differing ontogenies and timing of adult eclosion (Feder et al., 1993).

The activity of each host race is synchronized with the phenology of its host fruit. Adults of the haw race therefore eclose about ten days to two weeks after members of the apple race (Reissig and Smith, 1978; Feder et al., 1993). Genetic and mark-release-recapture studies on local Michigan populations indicate that haw flies may also reach sexual maturity more slowly than apple flies (Feder et al., 1993). Their eggs are thus deposited later in haw fruit. As a result eggs, larvae and pupae of the haw race are subjected to lower average daytime temperatures, cooler nights and progressively shorter day lengths than members of the apple race (Feder et al., 1993). Early developmental stages of both races must therefore adapt to quite different environmental conditions.

Adaptation to these temporal differences probably also involved the six allozyme loci that display allele frequency differences between local sympatric apple and haw populations (Feder et al., 
1988; Feder et al., 1990b). This is supported by the fact that the sampling of allelic variation among paired local collecting sites over several north-south transects indicates that these alleles independently track different local ambient temperature conditions experienced by each race (Feder et al., 1989; Feder et al., 1990a; Feder and Bush, 1991; Feder et al., 1993). We found a very high correlation between the number of growing degree days above $50^{\circ} \mathrm{F}$ and gene frequency at all six loci. We used $50^{\circ} \mathrm{F}$ because this temperature is the approximate lower threshold condition for pupal development in $R$. pomonella. The tight relationship between temperature and host race associated alleles suggests that they have biochemical advantages within certain temperature ranges similar to those reported for other insect allozymes (Bush et al., 1976; Watt et al., 1983; Kreitman and Hudson, 1991).

5. Inter-racial hybrid compatibility: Experimental crosses between the apple and haw races have revealed no evidence of hybrid incompatibility (Reissig and Smith, 1978; Prokopy and Bush, unpublished). There is indication of some reduced fertility among male and female hybrids resulting from crosses between $R$. pomonella and closely related species in the pomonella species group such as $R$. mendax (Feder et al., 1989a; Feder et al., 1989b; Bierbaum and Bush, 1990) and R. zephyria (McPheron, 1990a, $1990 \mathrm{~b}$ ), but not sufficient to inhibit potential gene flow if hybridization occurs in nature (McPheron, 1990a, 1990b). Crosses between $R$. pomonella and $R$. cornivora, which are distantly related to one another (Berlocher et al., submitted), produce few fertile offspring (Smith et al., 1993). In $R$. cerasi, cytoplasmically induced unidirectional sterility between parapatric races has been found (Boller and Bush, 1974; Boller et al., 1976).

\section{Sympatric Host Race Formation and Speciation in Rhagoletis}

As I have emphasized, host races of $R$. pomonella differ from one another in several biologically significant ways that promote the subdivision of populations adapted to different hosts. These adaptive changes include genetically based differences in host preferences and developmental rates. Undoubtedly, the host races differ in other subtle ways we have yet to appreciate. The most significant byproduct of adapting to a new host is the emergence of a 
new mate recognition system under sympatric conditions that sets the stage for speciation.

Berlocher (1989) has discussed several ways host races may have evolved in $R$. pomonella. These involve single or multiple colonization events of apple by haw flies and their potential outcome with respect to the pattern of genetic divergence between the races. Exactly how long it took for genetic differences to evolve between the apple and haw races is unknown, but the process probably occurred over a short period of time. The appearance of resistance in many insect species throughout the world shortly after exposure to an insecticide, and the rapid gene-for-gene adaptation of the Hessian fly to new wheat cultivars attest to the speed that phytophagous parasites can adapt to exotic substrates and develop new, host-specific races (Diehl and Bush, 1984). Phytophagous insects undoubtedly harbor a great deal of genetic variation in alleles present at low frequency for a wide range of environmentally sensitive traits. When environmental conditions are altered or new habitats or hosts appear, these rare variants can quickly increase in frequency in response to selection. Much of the genetic variation in host recognition and preference contributing to a host shift in $R$. pomonella, therefore, probably existed in the haw population before apples were introduced to North America. Because host races are not reproductively isolated, initially there is sufficient gene flow accompanying a host shift to insure that alleles at most loci are shared. This certainly appears to be true for the apple and hawthorn races which share all electromorphs in common, including those that are rare. In the case of $R$. pomonella, the shift to a new host has not resulted in a genetic bottleneck or genetic revolution, factors considered important in cases of peripatric speciation (Mayr, 1982). This lack of conspicuous genetic divergence should be true for most sympatric host races and, more importantly, species that have recently evolved from sympatric host races.

From the moment a new host is colonized, the web of selective forces acting on loci responsible for maintaining fitness is altered. Scott Diehl and I (1989), using computer simulations, reported that considerable progress toward speciation occurs when habitat specific mating is coupled with fitness tradeoffs between hosts. However, we also showed that unless host selection is almost error free, gene flow will usually be sufficient to inhibit completion of the 
speciation process. The populations exploiting the new and old hosts are destined to remain host races, occasionally exchanging genes, unless other adaptive genetic changes intervene. Johnson et al. (submitted) found that gene flow is eliminated and speciation rapidly completed if slight differences in the frequency of nonhabitat assortative mating alleles arise between host races in addition to loci for habitat preference and fitness involved in host race formation. For instance, differences in non-host recognition traits, such as a mating pheromone, cuticle hydrocarbons, courtship displays, or time of eclosion, are sufficient to drive the speciation process to completion under biologically realistic conditions of selection, even when all loci have relatively low penetrance.

Rhagoletis pomonella is an excellent model for illustrating how other Rhagoletis species evolved in the absence of geographic isolation. Cryptic sister species in Rhagoletis are almost always sympatric and found in species groups in which speciation was accompanied by a shift to a new host (Bush, 1969b). They most likely evolved sympatrically by first establishing a new host race via a host shift. The resulting reduced gene flow between the races allowed each host race to adapt somewhat to its respective host plant. Speciation was completed with the acquisition of genetically based differences in traits responsible for non-host associated assortative mating.

There are still several unanswered questions regarding the process of sympatric host race formation and speciation in Rhagoletis. We know little about the mode of origin of new host races. Was the apple race established from a single colonization event or have many independent host shifts throughout the range of $R$. pomonella established locally adapted apple race colonies? The former mode of race formation should result in a genetically homogeneous population throughout the range of the apple race. The latter should produce several genetically distinct parapatric or allopatric subpopulations (Berlocher, 1989).

Another intriguing problem is the role and outcome of hybridization that occurs between closely related species of Rhagoletis. We now know that $R$. pomonella and $R$. zephyria hybridize at a low level where their ranges overlap (McPheron, 1990a, 1990b; Williams and Bush, unpublished). A similar pattern of interspecific hybridization and gene flow has been noted 
between sympatric populations of Drosophila heteroneura and $D$. silvestris in Hawaii without losing their species identity (Carson and Kaneshiro, 1989). We do not know how common or what effect hybridization has on the evolution of closely related animal species. Some gene leakage must take place across species boundaries from time to time. Interspecific hybridization is relatively common in plants and may result in the evolution of new races or species which exploit novel habitats (Grant, 1981). The same phenomenon may be more widespread in insects than is now realized. As far as the evolution of host races is concerned in Rhagoletis and other insect parasites, small levels of gene flow might provide novel recombinants that are preadapted to a new host and initiate a host shift.

I wish to emphasize that not all Rhagoletis species have speciated sympatrically. Morphologically distinct sister species, such as those with conspicuous differences in color as well as wing patterns and body markings used in visual courtship displays, are generally parapatric or allopatric (Bush, 1969b). They belong to species groups in which the larvae of all species within the group infest fruit of the same host plant species as, for example, members of the $R$. suavis species group which attack only walnuts (Juglans spp.). Speciation in these flies is likely the result of allopatric isolation.

The pattern of sympatric speciation occurring in Rhagoletis may be typical not only of many insect habitat and host specialists, but also for many parasitic mites, crustaceans and nematodes that are often tightly linked to their hosts for feeding and mating (Bush, 1993). As a rough estimate, over $70 \%$ of all insect species are parasites or parasitoids (Price, 1980). In groups that have been well studied, most are relatively host specific and many rendezvous on their hosts for courtship and mating. Insects are now recognized as the most abundant class of metazoans, with some estimates reaching 30 million species or over $95 \%$ of all multicellular animals. The apparent ability of many insects such as Rhagoletis to rapidly speciate sympatrically supports the view that non-allopatric speciation has and continues to contributed significantly to this lopsided species diversity. 
SUMmaRY

I present an overview of the evidence for sympatric host race formation in the tephritid fruit fly Rhagoletis pomonella whose larvae originally fed on the fruits of hawthorn (Crataegus). Individuals of this species shifted to apples (Malus) approximately 150 years ago and established a genetically distinct host race. Because mating is confined to the host plant, mate choice is determined by host choice in these flies. Host preference and adaptations associated with host plant utilization, therefore, constitute the major components of the mate recognition system of each host race. Host plant preference is based primarily on olfactory cues, and is genetically controlled. Also, the synchronization of adult emergence of each host race with host fruit phenology has resulted in genetic divergence of eclosion times and adaptations to different seasonal ambient temperatures. These differences in the mate recognition systems, which have evolved in the absence of geographic isolation, reduce the chance of interbreeding between host races. I discuss conditions that promote the sympatric conversion of such host races into species.

\section{ACKNOWLEDGMENTS}

I thank Stewart Berlocher, Jeffery Feder, John Jenkins, Yue Ming, Ronald Prokopy and Jim Smith who reviewed earlier versions of this paper. I have benefited from their helpful comments and suggestions. I also thank Dolores Bush for assistance in preparing the manuscript. Much of the research cited here could not have been accomplished without contributions from my students and research associates over the years as well as support from the National Science Foundation, the National Institutes of Health, the USDA Competitive Grants Committee and direct support to me by Michigan State University.

\section{REFERENCES}

Aluja, M. AND Boller, E. F.

1992. Host marking pheromone of Rhagoletis cerasi: Foraging behavior in response to synthetic pheromonal isomers. J. Chem. Ecol. 18: $1299-1311$. 
Aluja, M. And Prokopy, R. J.

1992. Host search behavior by Rhagoletis pomonella flies: inter-tree movement patterns in response to wind-borne fruit volatiles under field conditions. Physiol. Entomol. 17: 1-8.

Averill, A. L. AND Prokopy, R. J.

1989. Host marking pheromones. pp 207-219. In Robinson, A. S. and Hooper, G. (eds), Fruit Flies, Their Biology, Natural Enemies and Control. World Crop Pests. 3A. Elsevier, Amsterdam.

Averill, A. L., Reissig, W. H. ANd Roelofs, W. L.

1988. Specificity of olfactory responses in the tephritid fruit fly, Rhagoletis pomonella. Entomol. exp. appl. 47: 211-222.

BARNES, M. M.

1959. Radiotracer labeling of a natural tephritid population and flight range of the walnut husk fly. Ann. Entomol. Soc. Am. 52: 90-92.

Benjamin, F. H.

1934. Description of some native trypetid flies with notes on their habits. U. S. Dept. Agr. Tech. Bull. No. 401: 95 pp.

BERLOCHER, S. H.

1989. The complexities of host races and some suggestions for their identification by enzyme electrophoresis. pp 51-68. In Loxdale, H. D. and den Hollander, J. (eds), Electrophoretic studies of agricultural pests. Syst. Assoc. Spec. Vol. 39: Oxford University Press, Oxford.

Berlocher, S. H. AND Bush, G. L.

1982. An electrophoretic analysis of Rhagoletis (Diptera: Tephritidae) phylogeny. Syst. Zool. 31: 136-155.

BERLOCHER, S. H. AND ENQUist, M.

1993. Geographic and host plant range of the apple maggot fly in Texas. J. Kans. Entomol. Soc. 66: 145-166.

Berlocher, S. H., McPheron, B. A., Feder, J. L. And Bush, G. L. Phylogeny of the Rhagoletis pomonella (Diptera: Tephritidae) species complex: Evidence from enzyme electrophoresis. Ann. Entomol. Soc. Amer. submitted.

Bierbaum, T. J. AND Bush, G. L.

1990. Genetic differentiation in the viability of sibling species of Rhagoletis fruit flies on host plants, and the influence of reduced hybrid viability on reproductive isolation. Entomol. exp. appl. 55: 105-118.

BOLLER, E.

1979. Potentials and limitations of genetic control of agricultural pests. Proc. IOBC/WPRS Symp. on Integrated Control, Vienna. pp 145-149.

1987. Genetic control. Integrated Pest Management. pp 161-187. Academic Press Ltd, New York.

Boller, E. F. AND Bush, G. L.

1974. Evidence for genetic variation in populations of the European cherry fruit fly, Rhagoletis cerasi (Diptera: Tephritidae) based on physiological parameters and hybridization experiments. Entomol. exp. appl. 17: 279-293.

Boller, E. AND Prokopy, R. J.

1976. The biology and management of Rhagoletis. Ann. Rev. Entomol. 112: 289-303. 
Boller, E. F., Russ, K., Vallo, V. ANd Bush, G. L.

1976. Incompatible races of European cherry fruit fly, Rhagoletis cerasi (Diptera: Tephritidae), their origin and potential use in biological con-

Boyce, A. M. trol. Entomol. exp. appl. 20: 237-247.

1934. Bionomics of the walnut husk fly, Rhagoletis completa. Hilgardia 8: 363-579.

BRITTON, W. E.

1906. Apple maggot infesting huckleberries. 5th Rept. St. Entomol., Conn. Agr. Expt. Sta. Ann. Rept. (1905) 29: 1-260.

Bush, G. L.

1966. The taxonomy, cytology, and evolution of the genus Rhagoletis in North America (Diptera, Tephritidae). Bull. Mus. Comp. Zool. 134: 431-562.

1969a. Sympatric host race formation and speciation in frugivorous flies of the genus Rhagoletis (Diptera, Tephritidae). Evolution 23: 237-251.

1969b. Mating behavior, host specificity, and the ecological significance of sibling species in frugivorous flies of the genus Rhagoletis (Diptera, Tephritidae). Amer. Nat. 103: 669-672.

1974. The mechanism of sympatric host race formation of the true fruit flies (Tephritidae). pp 3-23. In White, M. J. D. (ed), Genetic Mechanisms of Speciation in Insects. Australia and New Zealand Book Co., Sydney.

1975. Sympatric speciation in phytophagous parasitic insects. pp 187-206. In Price, P. (ed), Evolutionary Strategies of Parasitic Insects and Mites, Plenum Pub. Corp., New York.

1993. A reaffirmation of Santa Rosalia, or why are there so many kinds of small animals? In Lees, D. R. and Edwards, D. (eds), Evolutionary Patterns and Processes. Academic Press, London. in press.

Bush, G. L. AND DIEHL, S. R.

1982. Host shifts, genetic models of sympatric speciation and the origin of parasitic insect species. pp 297-305. In Visser, J. H. and Minks, A. K. (eds), Proc. 5th Inter. Symp. on Insect-Plant Relationships. Pudoc, Wageningen, Netherlands.

Bush, G. L., Feder, J. L., Berlocher, S. H., McPheron, B. A., Smith, D. C. AND

Chilcote, C. A.

1989. Sympatric origins of $R$. pomonella. Nature 339: 346 .

Bush, G. L., NeCK, R. W. AND Kitto, G. B.

1976. Screwworm eradication: Inadvertent selection for noncompetitive ecotypes during mass rearing. Science 141: 491-493.

Carson, H. L. AND Kaneshiro, K. Y.

1989. Natural hybridization between the sympatric Hawaiian species Drosophila silvestris and Drosophila heteroneura. Evolution 43: 190-203.

CRNJAR, R. M. AND PROKOPY, R. J.

1982. Morphological and electrophysiological mapping of tarsal chemoreceptors of oviposition-deterring pheromone in Rhagoletis pomonella flies. J. Insect Physiol. 28: 393-400.

Curran, C. H.

1932. New North American Diptera with notes on others. Amer. Mus. Nov. 526: 1-13. 
Dean, R. W. AND Chapman, P. J.

1973. Bionomics of the apple maggot in eastern New York. Search Agric. (Geneva, N. Y.) 3: 1-62.

DiEHL, S. R. AND Bush, G. L.

1984. An evolutionary and applied perspective of insect biotypes. Ann. Rev. Entomol. 29: 471-504.

1989. The role of habitat preference in adaptation and speciation. pp 345-365. In Otte, D. and Endler, J. (eds), Speciation and its Consequences. Sinauer, Sunderland, Massachusetts.

FEDER, J. L. AND BuSH, G. L.

1989. A field test of differential host-plant usage between two sibling species of Rhagoletis pomonella fruit flies (Diptera: Tephritidae) and its consequences for sympatric speciation. Evolution 43: 1813-1819.

1991. Genetic variation among apple and hawthorn host races of Rhagoletis pomonella (Diptera: Tephritidae) across an ecological transition zone. Entomol. exp. appl. 59: 249-265.

Feder, J. L., Chilcote, C. A. And Bush, G. L

1988. Genetic differentiation between sympatric host races of Rhagoletis pomonella. Nature 336: 61-64.

1989a. Gene frequency clines for host races of Rhagoletis pomonella in midwestern United States. Heredity 63: 245-266.

$1989 \mathrm{~b}$. Are the apple maggot, Rhagoletis pomonella and the blueberry maggot, $R$. mendax (Diptera: Tephritidae) distinct species? Implications for sympatric speciation. Entomol. exp. appl. 51: 113-123.

1990a. The geographic pattern of genetic differentiation between host associated populations of Rhagoletis pomonella (Diptera, Tephritidae) in the eastern United States and Canada. Evolution 44: 570-594.

1990b.Regional, local and microgeographic allele frequency variation between apple and hawthorn populations of Rhagoletis pomonella in western Michigan. Evolution 44: 595-608.

Feder, J. L., Hunt, T. A. AND Bush, G. L.

1993. The effects of climate, host plant phenology and host fidelity on the genetics of apple and hawthorn infesting races of Rhagoletis pomonella. Entomol. exp. appl. in press.

Feder, J. L., Opp, S. B., Wlazlo, B., Spisak, S., Reynolds, C. and Go, W. The role of host fidelity in sympatric race formation in the apple maggot fly, Rhagoletis pomonella. in prep. a.

FEDER, J. L., REYNOLdS, C. AND Go, W.

Enemy free space as a factor affecting host race formation in Rhagoletis pomonella (Diptera: Tephritidae). in prep. $\mathrm{b}$.

Fein, B. L., ReIssig, W. H. AND Roelofs, W. L.

1982. Identification of apple volatiles attractive to the apple maggot, Rhagoletis pomonella. J. Chem. Ecol. 8: 1473-1487.

Frey, J. E., Bierbaum, T. J. AND Bush, G. L.

1992. Differences among sibling species Rhagoletis mendax and $R$. pomonella (Diptera: Tephritidae) in their antennal sensitivity to host fruit compounds. J. Chem. Ecol. 18: 2001-2023.

FREY, J. E. AND Bush G. L.

1990. Rhagoletis sibling species and host races differ in host odor recognition. Entomol. exp. appl. 57: 123-131. 
Futuyma, D. J. AND Mayer, G. C.

1980. Non-allopatric speciation in animals. Syst. Zool. 29: 254-271.

GRANT, V.

1981. Plant Speciation. New York, Columbia University Press.

Guerin, P. M., Remund, U., Boller, E. F., Katsoyannos, B. and Delrio, G.

1982. Fruit fly electroantennogram and behavior responses to some generally

Hall, J. A. occurring fruit volatiles. pp 248-251. CEC/IOBC. Athens, Greece.

1934. Further observations on the biology of the apple maggot (Rhagoletis pomonella Walsh). Rept. Entomol. Soc. Ont. 69: 53-58.

ILLINGWORTH, J. F.

1912. A study of the biology of the apple maggot (Rhagoletis pomonella), together with an investigation of methods of control. Cornell Univ.

JAENIKE, J. Agr. Expt. Sta. Bull. 324: 129-187.

1981. Criteria for ascertaining the existence of host races. Amer. Nat. 117: 830-834.

Johnson, P., Bush, G. L., AND Hoppensteadt, F.

Conditions for sympatric speciation: A diploid model incorporating habitat fidelity and non-habitat assortative mating. submitted.

Kreitman, M., AND Hudson, R. R.

1991. Inferring the evolutionary histories of the ADH and ADH-DUP loci in Drosophila melanogaster from patterns of polymorphism and divergence. Genetics 127: 565-582.

LIENK, S. E.

1970. Apple maggot infesting apricot. J. Econ. Entomol. 63: 1684.

Maxwell, C. W. AND Parsons, E. C.

1968. The recapture of marked apple maggot adults in several orchards from one release point. J. Econ. Entomol. 61: 1157-1159.

MAlAVASI, A. AND PROKOPY, R. J.

1992. Effect of food deprivation on the foraging behavior of Rhagoletis pomonella (Diptera: Tephritidae) females for food and host hawthorn fruit. J. Entomol. Sci. 27: 185-193.

MAYR, E.

1970. Populations, Species, and Evolution. Belknap Press, Cambridge, MA.

1982. Processes of speciation in animals. pp 1-19. In Barigozzi, C. (ed) Mechanisms of Speciation. Alan R. Liss, New York.

McPheron, B. A.

1990a. Genetic structure of apple maggot fly (Diptera: Tephritidae) populations. Ann. Entomol. Soc. Am. 83: 568-577.

1990b. Implications of genetic variation in western apple maggots for understanding biology. pp 37-49. In Dowell, R. V., Wilson, L. T., and Jones, V. P. (eds), Apple Maggot in the West: History, Biology, and Control. Univ. Calif. Div. Agr. Nat. Res. Publ. 3341.

McPheron, B. A., SMith, D. C. AND Berlocher, S. H.

1988. Genetic differences between host races of the apple maggot fly. Nature 336: 64-66.

Messina, F. J. AND Jones, V. P.

1990. Relationship between fruit phenology and infestation by apple maggot (Diptera: Tephritidae) in Utah. Ann. Entomol. Soc. Amer. 83: 742-752. 
Moericke, V., Prokopy, R. J., Berlocher, S. And Bush, G. L.

1975. Visual stimuli eliciting attraction of Rhagoletis pomonella (Diptera: Tephritidae) flies to trees. Entomol. exp. appl. 18: 497-507.

Neilson, W. T. A. ANd McAllan, J. W.

1965. Effects of mating on fecundity of the apple maggot, Rhagoletis pomonella (Walsh). Canad. Entomol. 97: 276-279.

O'Kane, W. C.

1914. The Apple Maggot. New Hampshire Exp. Sta. Bull. 171: 1-120.

Opp, S. B. AND PROKOPY, R. J.

1986. Variation in laboratory oviposition by Rhagoletis pomonella (Diptera: Tephritidae) in relation to mating status. Ann. Entomol. Soc. Amer. 79: $705-710$.

1987. Seasonal changes in resightings of marked, wild Rhagoletis pomonella (Diptera: Tephritidae) flies in nature. Fla. Entomol. 70: 449-457.

PAPAJ, D. R. AND PRokopy, R. J.

1986. Phytochemical basis of learning in Rhagoletis pomonella and other herbivorous insects. J. Chem. Ecol. 12: 1125-1143.

1988. The effect of prior adult experience on components of habitat preference in the apple maggot fly (Rhagoletis pomonella). Oecologia 76: $538-543$.

PREE, D. J.

1977. Resistance to development of larvae of apple maggot in crab apples. J. Econ. Entomol. 70: 611-614.

Price, P. W.

1980. Evolutionary Biology of Parasites. Princeton University Press, Princeton, NJ.

PROKOPY, R. J.

1968. The influence of photoperiod, temperature and food on the initiation of diapause in the apple maggot. Canad. Entomol. 100: 318-329.

1972. Evidence for a marking pheromone deterring repeated oviposition in apple maggot flies. Environ. Entomol. 1: 323-326.

1975. Mating behavior in Rhagoletis pomonella. V. Virgin female attraction to male odor. Canad. Entomol. 107: 905-908.

1976. Stimuli influencing trophic relations in Tephritidae. Colloques Internationaux du C. N. R. S. 265: 305-336.

1977. Attraction of Rhagoletis flies (Diptera: Tephritidae) to red spheres of different sizes. Canad. Entomol. 109: 593-596.

1981. Oviposition-deterring pheromone system of apple maggot flies. pp 477-494. In Mitchell, E. R. (ed.), Management of Insect Pests with Semiochemicals: Concepts and Practice. Plenem Press, New York.

Prokopy, R. J., Averill, A. L., Cooley, S. S. And Roitberg, C. A.

1982. Associative learning in egglaying site selection by apple maggot flies. Science 218: 76-77.

Prokopy, R. J., BennetT, E. W. And Bush, G. L.

1971. Mating behavior in Rhagoletis pomonella (Diptera: Tephritidae). I. Site of assembly. Canad. Entomol. 103: 1405-1409.

Prokopy, R. J. AND Berlocher, S. H.

1980. Establishment of Rhagoletis pomonella (Diptera: Tephritidae) on rose hips in southern New England. Canad. Entomol. 112: 1319-1320. 
PROKopy, R. J. AND BUSH, G. L.

1972a. Apple maggot infestation of pear. J. Econ. Entomol. 65: 597.

1972b. Mating behavior in Rhagoletis pomonella (Diptera: Tephritidae). III. Male aggregation in response to an arrestant. Canad. Entomol. 104: 275-283.

1973. Mating behavior in Rhagoletis pomonella (Diptera: Tephritidae). IV. Courtship. Canad. Entomol. 105: 873-891.

Prokopy, R. J., CoOley, S. S. AND OpP, S. B.

1989. Prior experience influences the fruit residence of apple maggot flies, Rhagoletis pomonella. J. Insect Behav. 2: 39-48.

Prokopy, R. J., Diehl, S. R. AND COOLEY, S. S.

1988. Behavioral evidence for host races in Rhagoletis pomonella flies. Oecologia 76: 138-147.

Prokopy, R. J., Moericke, V. ANd Bush, G. L.

1973. Attraction of apple maggot flies to odor of apples. Environ. Entomol. 2: 743-749.

Prokopy, R. J. AND PAPAJ, D. R.

1988. Learning of apple fruit biotypes by apple maggot flies. J. Insect Behav. 1: 67-74.

Reissig, W. H., Barnard, J., Weires, R. W., Glass, E. H. and Dean, R. W.

1979. Prediction of apple maggot fly emergence from thermal unit accumulation. Environ. Entom. 8: 51-54.

ReIsSig, W. H. AND SMITH, D. C.

1978. Bionomics of Rhagoletis pomonella in Crataegus. Ann. Entomol. Soc. Amer. 71: 155-159.

RIEDEL, H. AND HISLOP, R.

1985. Visual attraction of the walnut husk fly (Diptera: Tephritidae) to color rectangles and spheres. Environ. Entomol. 14: 810-814.

ROBERTSON, K. R., PHIPPS, J. B., ROHER, J. R.

1991. A synopsis of genera in Maloidae (Rosaceae). Syst. Bot. 16: 376-394.

Roitberg, B. D., Van Lenteren, J. C., Van Alphen, J. J. M., Galis, F. AND

PROKOPY, R. J.

1982. Foraging behavior of Rhagoletis pomonella, a parasite of hawthorn (Crataegus), in nature. J. Anim. Ecol. 51: 307-325.

SHEPARD, C. A.

1989. A brief history of the Practical Entomologist and its contributions to economic entomology. Entomol. News 100: 212-223.

Shervis, L. J., Boush, G. M. AND Koval, C. F.

1970. Infestation of sour cherries by apple maggot: confirmation of a previously uncertain host. J. Econ. Entomol. 63: 294-295.

SMITH, D. C.

1988a. Reproductive differences between Rhagoletis (Diptera: Tephritidae) fruit parasites of Cornus amomum and C. florida (Cornaceae). N. Y. Entomol. 96: 146-158.

1988b. Heritable divergence of Rhagoletis pomonella host races by seasonal asynchrony. Nature 336: 66-68.

SMITH, D. C. AND PROKOPY, R. J.

1980. Mating behavior in Rhagoletis pomonella. VI. Site of early season encounters. Canad. Entomol. 112: 489-495. 
Smith, D. C., Lyons, S. A. ANd Berlocher, S. H.

1993. Production and electrophoretic verification of $F_{1}$ hybrids between the sibling species $R$. pomonella and $R$. cornivora. Entomol. exp. appl. in press.

SNOw, W. A.

1894. Descriptions of North American Trypetidae, with notes. Kan. Univ. Quart. 2: 1159-1174.

STÄDlER, E. AND KATSOYANNOS, B. I.

1979. Das Markierungspheromon der Kirschfliege: Erste electrophysiologische Untersuchungen der Sinnesorgane. Mitt. Schweiz. Entomol. Ges. 52: 444.

Stanek, E. J. I., Diehl, S. R., Dgetluck, N., Stokes, M. E. And Prokopy, R. J.

1987. Statistical methods for analyzing discrete responses of insects tested repeatedly. Environ. Entomol. 16: 319-326.

WALSH, B. D.

1863. Observations on certain N. A. Neuroptera, by Hagen, M. D., of Koenigsberg, Prussia; translated from the original French MS, and published by permission of the author, with notes and descriptions of about twenty new N. A. species of Pseudoneuroptera. Proc. Entomol. Soc. Phila. 2: 167-272.

1864. On phytophagic varieties and phytophagic species. Proc. Entomol. Soc. Phila. 3: $403-430$.

1867. The apple-worm and the apple-maggot. J. Hort. 2: 338-343.

Watt, W. B., Cassin, R. C. AND Swan, M. S.

1983. Adaptation at specific loci. III. Field behavior and survivorship differences among Colias PGI genotypes are predictable from in vitro biochemistry. Genetics 103: 725-739.

Webster, R. P., Stoffolano, J. G. AND Prokopy, R. J.

1979. Long-term intake of protein and sucrose in relation to reproductive behavior of wild and laboratory cultured Rhagoletis pomonella. Ann. Entomol. Soc. Am. 72: 41-46.

ZWÖLFER, H. AND BUSH, G. L.

1984. Sympatrische und parapatrische Artbildung. Z. zool. Syst. Evolut. -forsch. 22: 211-233. 

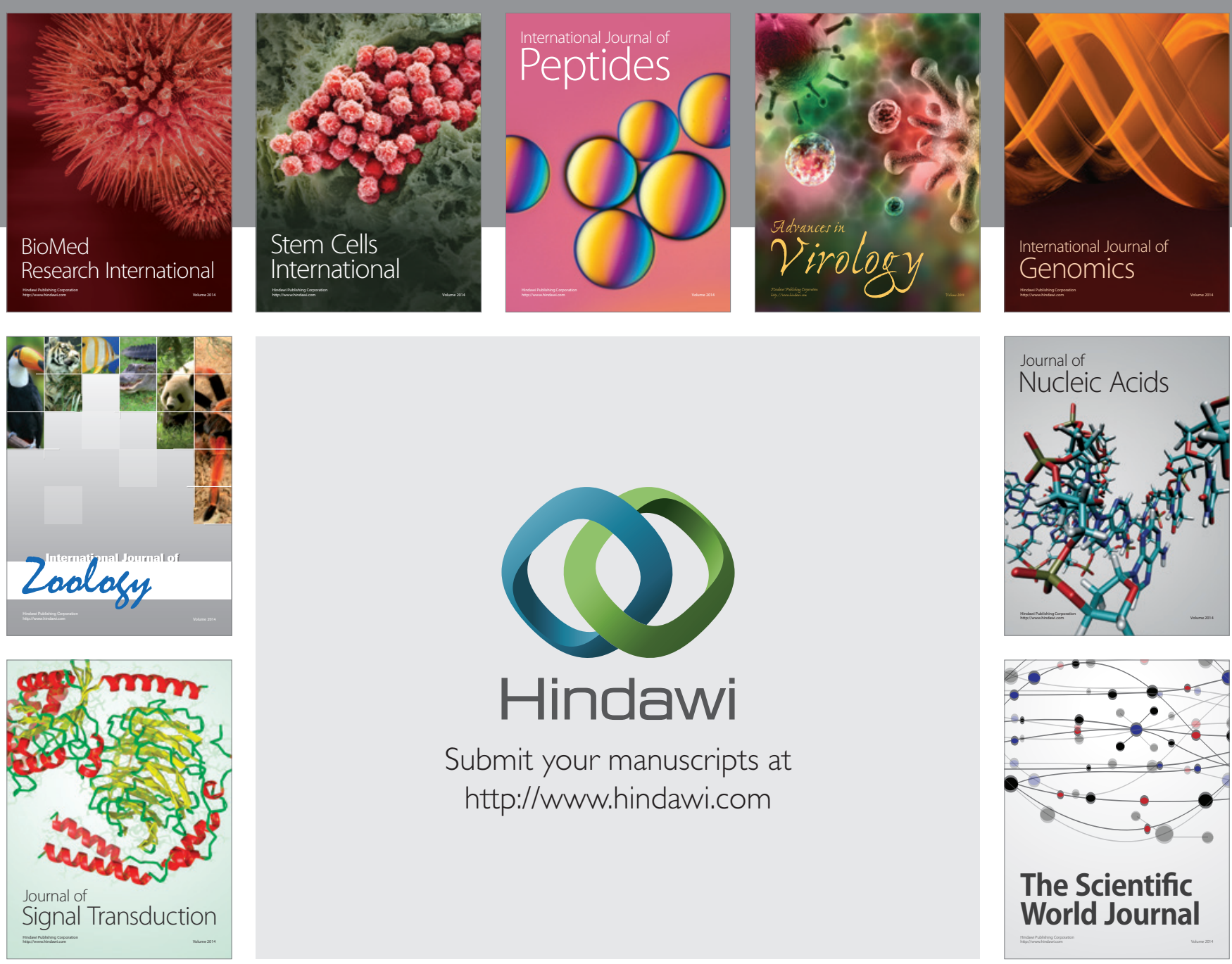

Submit your manuscripts at

http://www.hindawi.com
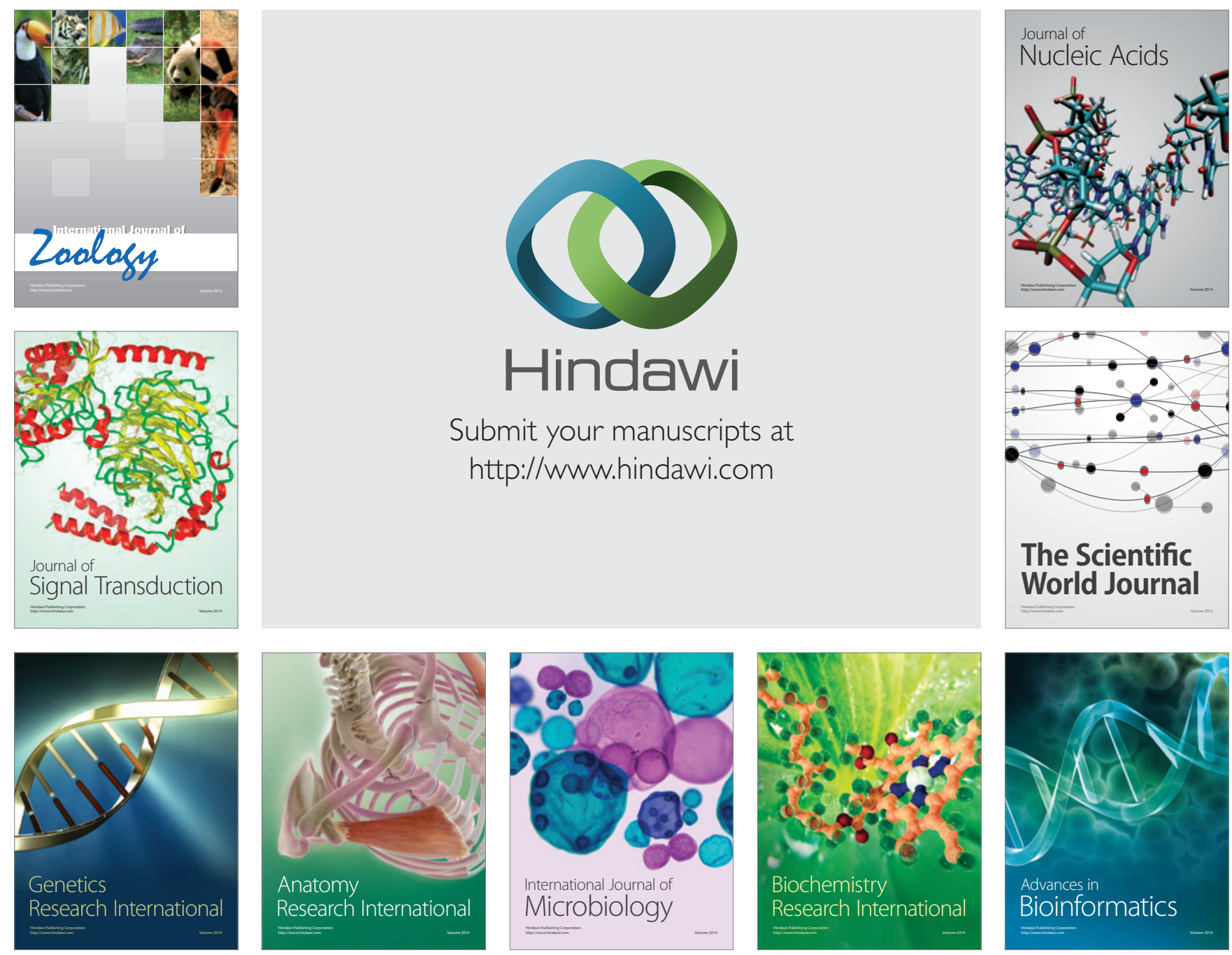

The Scientific World Journal
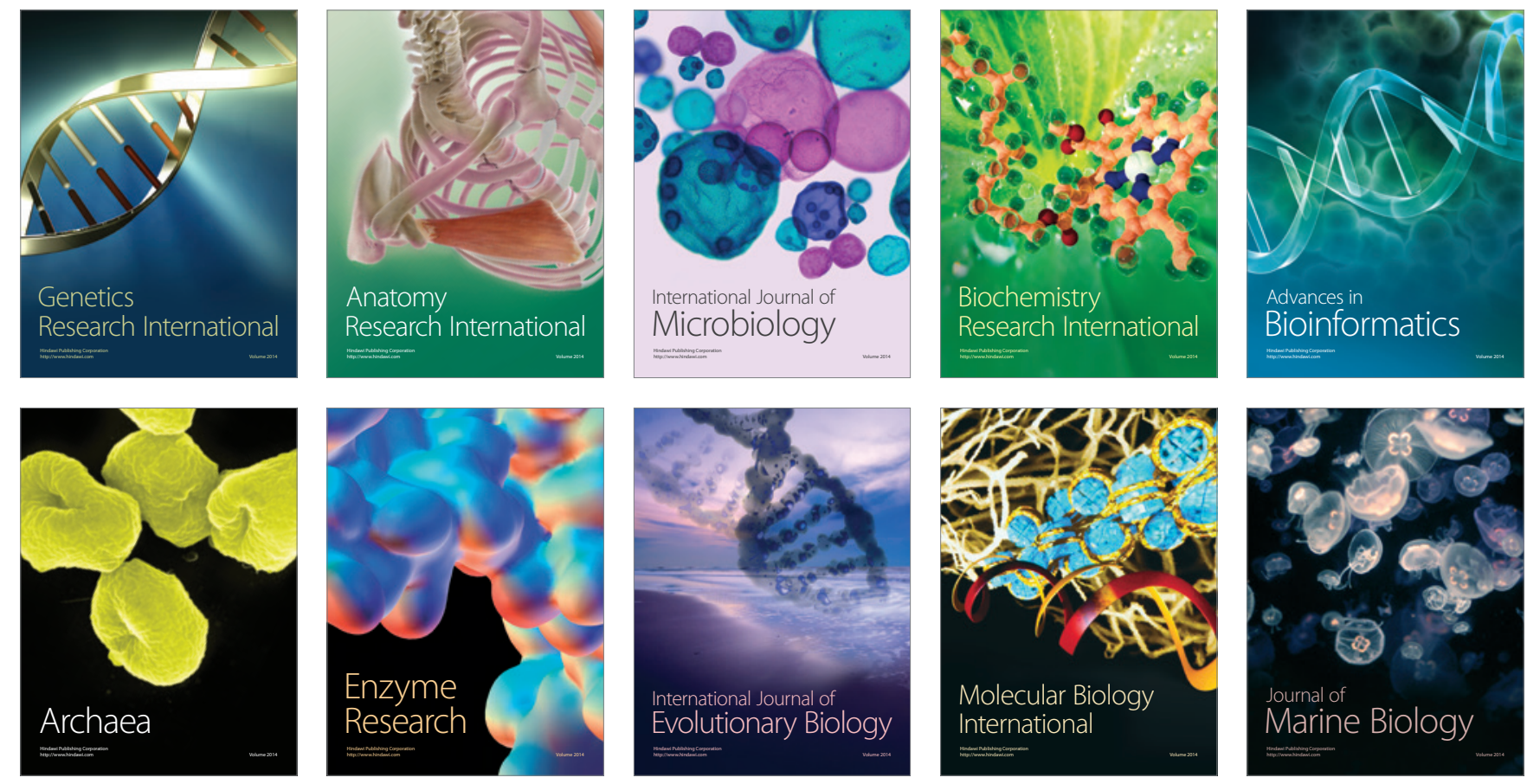